\title{
NILAI-NILAI MORAL DALAM SERAT WEDHATAMA DAN PENDIDIKAN BUDI PEKERTI
}

\author{
Sutrisna Wibawa \\ FBS Universitas Negeri Yogyakarta (e-mail: trisnagb@uny.ac.id)
}

\begin{abstract}
Abstrak: Moral Values in Serat Wedhatama and Moral Education. Moral values are the highest values with four main characteristics: responsibility, conscience, absolute obligation, and formality. They are also related to what should not be done due to the values that have to be highly praised. The moral values in Serat Wedhatama include, among others, simple life, affection, responsibility, conscience development, love to others, humbleness, not being proud, religious obedience by conforming to the religious rules and avoiding what is prohibited, good positions through sincere work everywhere, wealth through hardwork, and knowledge that other people can benefit from. Such values are absolute moral values that are fixed and formal in nature. Serat Wedhatama can be a main reference for the learning of local contents of the Javanese Language, Literature, and Culture because it contains moral values that can be used a basis for moral education.
\end{abstract}

Keywords: Serat Wedhatama, moral values

\section{PENDAHULUAN}

Sampai detik ini, Indonesia masih mengalami berbagai krisis. Krisis tersebut mendera berbagai bidang, mulai dari bidang ekonomi, sosial, politik, budaya, kesehatan, dan kemanusiaan yang terjadi secara terus-menerus, yang seakan-akan tidak ada jalan keluar. Bila membaca media cetak dan mengikuti berita-berita lewat media elektronik, banyak berita mengenai kelaparan, kesenjangan sosial, hingga kemiskinan yang secara ilmiah dapat dibuktikan dengan angka statistik. Di lain pihak, juga didengar krisis moral yang berkepanjangan, krisis di mana manusia tidak lagi mampu memahami perbedaan benar dan salah, atau tingkah laku yang baik. Demi mengejar kekuasaan, orang dengan ringannya mencederai orang lain, bahkan sampai menyebabkan orang lain meninggal. Sebut saja, misalnya kasus unjuk rasa di salah satu provinsi di Indonesia, hanya karena persoalan memperjuangkanpemekaran wilayah menyebabkan Ketua DPRD provinsi tersebut meninggal. Demikian juga, kasus yang sekarang tengah ditangani pengadilan seperti pembunuhan seorang pengusaha sehabis bermain golf, kasus kekerasan rumah tangga yang menimpa salah satu warga negara Indonesia di salah satu kasultanan di negara tetangga Indonesia, dan sederet kasus lainnya.

Dalam dunia pendidikan pun yang seharusnya sebagai penjaga nilai-nilai moral juga telah mengalami degradasi. Sebagai contoh kasus yang baru saja terjadi di salah satu provinsi di Indo- 
nesia, beberapa Kepala Sekolah Sekolah Menengah Atas berbuat melanggar norma-norma kejujuran hanya demi mengejar nilai ujian nasional (UN), kasus perkelahian remaja juga masih marak di kota-kota besar. Belum lama ini juga terjadi kasus yang mencoreng wajah pendidikan oleh komponen pendidikan itu sendiri. Ada kasus seorang remaja yang menggadaikan harga diri untuk memenuhi kebutuhan ekonomi. Ada kasus seorang wakil kepala sekolah yang melakukan pelecehan terhadap siswanya, padahal seorang guru seharusnya menjadi teladan, memberikan bimbingan dan pengawasan terhadap muridnya, malah membuat onar dengan melakukan hal yang tidak pantas dilakukan.

Di sisi lain, ada sebuah klinik dokter yang menjadi tempat aborsi. Telah banyak janin yang tidak berdosa dibunuh. Bahkan, Indoneisa menjadi negara yang paling banyak melakukan aborsi. Sangat ironis jika kita lihat, klinik yang seharusnya menjadi tempat untuk menyelamatkan nyawa menjadi tempat pembunuhan dan yang lebih menyakitkan hati lagi hal ini dilakukan oleh dokter yang notabene sebagai orang terdidik, yang telah menghabiskan uang puluhan juta ketika menempuh pendidikannya.

Untuk mengatasi permasalahanpermasalahan tersebut, bangsa Indonesia sebenarnya telah memiliki warisan luhur dari nenek moyang. Dalam berbagai budaya daerah di Indonesia terdapat kekayaan yang tidak ternilai harganya, yaitu kekayaan nilai-nilai kearifan lokal berupa ajaran moral yang tersimpan pada berbagai karya sastra la- ma. Ajaran moral itu merupakan kebijakan hidup, yang umumnya diwariskan melalui karya sastra, yang di dalamnya penuh keteladanan yang diwujudkan dalam bentuk ajaran. Salah satu karya sastra Jawa yang mengandung ajaran moral, yaitu Serat Wedhatama karya Mangku Negara IV. Dalam makalah ini dikaji nilai-nilai moral dalam Serat Wedhatama yang dimaksud.

\section{NILAI-NILAI MORAL}

Nilai adalah sesuatu yang kita iakan atau kita aminkan. Nilai selalu mempunyai konotasi positif (Bertens, 2004:139). Nilai setidaknya memiliki tiga ciri. Pertama, nilai berkaitan dengan subjek. Kalau tidak ada subjek yang menilai, maka tidak ada nilai juga. Entah manusia hadir atau tidak, gunung tetap meletus. Untuk dapat dinilai sebagai indah atau merugikan, letusan gunung itu memerlukan subjek yang menlai. Kedua, nilai tampil dalam suatu konteks praktis, di mana subjek ingin membuat sesuatu. Dalam pendekatan yang semata-mata teoretis, tidak akan ada nilai. Ketiga, nilai-nilai menyangkut sifat-sifat yang ditambah oleh subjek pada sifat-sifat yang dimiliki oleh objek. Nilai tidak dimiliki oleh objek pada dirinya. Objek yang sama bagi pelbagai subjek;dapat menimbulkan nilai yang berbeda-beda. Pembicaraan nilai tidak bisa dilepaskan dari nilai moral atau etis. Nilai moral merupakan nilai tertinggi. Nilai moral memiliki ciri-ciri (1) berkaitan dengan pribadi manusia yang bertanggung jawab; (2) berkaitan dengan hati nurani; (3) mewajibkan manusia secara absulut yang tidak bisa ditawar-tawar; dan (4) 
bersifat formal (Bertens, 2004:143-147). Nilai moral berkaitan juga dengan apa yang seyogianya tidak dilakukan karena berkaitan dengan prinsip moralitas yang ditegakkan (Wiramihardja, 2007: 158). Hal itu mengacu juga pada Suyadi (1999:21) yang mengartikan nilai dalam arti baik atau benar berkaitan dengan masalah etis atau moral. Menurut Suseno (1990:14) etika memberikan pemahaman tentang kesusilaan, sedangkan moral memberikan ajaran tentang kesusilaan ataupun kebaikan.

Lebih lanjut Scheler (Susena, 2008: 16-18) menyatakan bahwa nilai bersifat apriori. Maksudnya, apa arti sebuah nilai, misalnya enak, jujur atau kudus, kita ketahui bukan karena suatu pengalaman, secara aposteriori, melainkan kita ketahui begitu kita sadar akan nilai itu. Manusia tidak menciptakan nilainilai, melainkan menemukan mereka. Menurut Scheler nilai dapat diungkap bukan dengan pikiran, melainkan dengan suatu perasaan intensional. Perasaan di sini tidak dibatasi pada perasaan fisik atau emosi, melainkan mirip dengan paham rasa dalam budaya Jawa, sebagai keterbukaan hati dan budi dalam semua dimensi. Perasaan itu intensional karena setiap nilai ditangkap melalui perasaan yang terarah tepat padanya. Menurut Scheler ada empat gugus nilai, yaitu (1) nilai-nilai sekitar yang enak dan yang tidak enak; (2) nilai-nilai vital di mana paling utama adalah nilai yang luhur dan yang hina dan di mana saja termasuk keberanian dan sifat takut, perasaan sehat dan tidak enak badan, dan sebagainya; (3) nilai-nilai rohani yang indah dan yang jelek atau nilai estetis, nilai-nilai yang benar dan tidak benar atau nilai keadilan, dan nilai kebenaran murni, yaitu kebernilaian pengetahuan demi pengetahuan itu sendiri dan bukan karena ada manfaatnya; dan (4) nilai-nilai sekitar yang kudus dan yang profane yang dihayati manusia dalam pengalaman religius. Di luar empat gugus nilai tersebut, ada dua gugus nilai yang tidak mempunyai isi sendiri (nilainya ditentukan oleh nilai yang menjadi tujuan akhir), yaitu nilai kegunaan dan nilai moral. Nilai kegunaan menunjuk pada sesuatu itu bernilai jika berguna dan nilai moral seperti yang baik dan yang jahat.

Dalam sumber yang lain, Sutan Tidakdir Alisyabana (Suseno, 2005:135) menyebutkan ada enam gugus nilai, yaitu (1) nilai-nilai teoretis atau gugus ilmu pengetahuan yang dinilai melalui tolok ukur benar-salah; (2) nilai-nilai ekonomis atau gugus nilai-nilai ekonomi yang dapat dinilai apakah sesuatu itu menguntungkan atau tidak atau kriteria untung-rugi; (3) nilai-nilai religius atau gugus nilai agama yang merupakan nilai tertinggi; (4) nilai-nilai estetik atau nilai gugus seni yang dapat dilihat dari indah tidak indahnya sesuatu; (5) nilai-nilai politis atau gugus nilai kuasa di mana yang bernilai positif adalah kekuasaan dan yang negatif ketertundukan; dan (6) nilai-nilai sosial atau gugus nilai solidaritas, yang merupakan nilai yang menentukan positif apa negatif dalam hubungan dengan orang lain. Enam gugus nilai itu melalui pelbagai konfigurasi dapat menentukan sistem nilai atau sistem moral khas setiap kepribadian, setiap kelompok sosial, dan setiap kebudayaan. 
Dalam makalah ini yang dimaksud nilai moral menunjuk pengertian sebagaimana dikatakan oleh Bertens bahwa nilai memiliki tiga ciri, yaitu nilai berkaitan dengan subjek, nilai tampil dalam suatu konteks praktis, dan nilai menyangkut sifat-sifat yang ditambah oleh subyek pada sifat-sifat yang dimiliki oleh objek. Nilai moral merupakan nilai tertinggi. Nilai moral memilik ciriciri (1) berkaitan dengan pribai manusia yang bertanggung jawab; (2) berkaitan dengan hati nurani; (3) mewajibkan manusia secara absulut dan tidak bisa ditawar-tawar; dan (4) bersifat formal. Nilai moral berkaitan juga dengan apa yang seyogianya tidak dilakukan karena berkaitan dengan prinsip moralitas yang ditegakkan. Jadi, inti dari nilai moral adalah nilai dalam arti "baik".

Konsep kata "baik" dapat dilihat dari berbagai pandangan. George Rdward Moore (Suseno, 2008:1-3) mengatakan bahwa kata "baik" adalah kata kunci moralitas. Kata "baik" merupakan kata dasar yang tidak dapat direduksikan kepada sesuatu yang lebih mendalam lagi. "Baik" merupakan sifat primer yang tidak terdiri atas bagian-bagian lagi, dan karena itu tidak dapat dianalisis. Kata "baik" merupakan etika yang paling mendasar. Kata "baik" kebalikannya adalah "buruk".

Dalam buku berujudul Ethics yang ditulis oleh Harry J. Gensler (1998), dibahas sepuluh aliran yang memaknai kata "baik" sepertti dideskripsikan berikut ini. Aliran pertama adalah Cultural Relativism (Gensler, 1998:11-20). Menurut aliran ini, baik dan buruk adalah relatif. Kata baik dimaknai sebagai sesuatu yang secara sosial telah disetujui oleh mayoritas dalam suatu budaya. Prinsip-prinsip moral didasarkan atas norma-norma masyarakat. Di sini tidak ada standar yang paling baik, setiap putusan yang benar atau salah adalah murni sebuah produk dari masyarakatnya. Aliran kedua adalah subjectivism (Gensler, 1998:21-32). Menurut subjectivism, keputusan moral adalah penjelasan dari apa yang kita rasakan. Jika kita mengatakan sesuatu itu baik karena kita memang merasa bahwa sesuatu itu bagus. Di sini, moralitas sangat berkaitan dengan perasaan pribadi seseorang dan emosi yang dirasakan. Aliran ketiga adalah Supernaturalism (Gensler, 1998: 33-45). Supernaturalism mengatakan bahwa moral hukum menjelaskan kehendak Tuhan. Supernaturalism berpendapat bahawa Hukum moral Tuhan akan menjelaskan: "X adalah baik" berarti "Allah menghendaki X." Supernaturalism merupakan etika berdasarkan agama. Aliran keempat adalah Intuitionism (Gensler, 1998:46-57). Intuitionism adalah aliran yang mengangkat persoalan moral berdasarkan intuisi. Menurut Intuitionism, kebenaran tidak dapat didefinisikan. Intuitionism mengakui adanya kebenaran objektif, akan tetapi kebenaran itu tidak dapat dijelaskan dan hanya diketahui secara langsung oleh orang yang peka atau dewasa moral berkat kemampuan intuitif mereka. Aliran kelima adalah Emotivism (Gensler, 1998: 58-70). Emotivism menyatakan bahwa masalah moral itu hanyalah perkara perasaan (emotion) saja. Emotivism melihat sebuah keputusan moral sebagai ekspresi perasaan, bukan pernyataan benar-benar "benar" atau "tidak benar". 
Baik menurut emotivism merupakan ekspresi perasaan.

Aliran keenam adalah prescriptivism (Gensler, 1998:71-83). Prescriptivism menyatakan bahwa ungkapan moral itu adalah keinginan yang diuniversalkan, misalnya penilaian "aborsi itu tidak bermoral", merupakan ungkapan bahwa saya tidak akan melakukan aborsi sekaligus ajakan agar orang lain tidak melakukan aborsi. Aliran ketujuh adalah golden rule (Gensler, 1998: 103-121). Aliran ini memperlakukan orang lain atau kita karena kita diperlakukan dalam situasi yang sama. Jadi, menurut golden rule tindakan moral diterapkan dengan cara kita memperlakukan orang lain seperti kita diperlakukan oleh orang lain. Aliran kedelapan adalah moral rationality (Gensler, 1998:122-137). Moral rationality memerlukan konsistensi, termasuk mengikuti kaidah. Moral rationality juga memerlukan unsurunsur lainnya, seperti pengetahuan dan imajinasi. Pengajaran moral rationality akan membantu anak-anak untuk lebih rasional dalam berpikir moral mereka yang merupakan bagian penting dari pendidikan moral. Ini terutama penting untuk mengajar lima perintah moral berpikir rasional, yaitu (1) membuat keputusan yang tepat; (2) hidup harmonis dengan moral kepercayaan, yang membuat mirip dengan tindakan serupa, (3) menempatkan diri di tempat orang lain, dan (4) memperlakukan orang lain seperti kita ingin diperlakukan. Aliran $k e-$ sembilan adalah consequentialism (Gensler, 1998:138;156). Consequentialism adalah aliran yang mengajarkan kepada kita untuk melakukan tindakan apa pun yang mempunyai konsekuensi atau dampak terbaik. Ada kalanya seorang consequentialism dapat melakukan kebohongan jika lebih dapat mendatangkan kebaikan. Aliran yang terkenal dari consequentialism adalah utilitarism, yang menyatakan bahwa kita harus melakukan sesuatu yang bisa memberikan dampak lebih baik dan menyingkirkan dampak yang tidak baik bagi tindakan kita. Aliran kesepuluh adalah nonconsequentialism (Gensler, 1998:157-174). Nonconsequentialism mengatidakan bahwa beberapa jenis tindakan (seperti membunuh atau melanggar janji yang bersalah) yang salah dalam diri mereka sendiri, dan bukan hanya karena mereka telah salah konsekuensi buruk. Halhal seperti itu mungkin exceptionlessly salah, atau mungkin saja ada beberapa independen moral berat terhadap mereka.

\section{NILAI-NILAI MORAL DALAM SE- RAT WEDHATAMA}

Secara semantic, Serat Wedhatama terdiri dari tiga suku kata, yaitu: serat, wedha dan tama. Serat berarti tulisan atau karya yang berbentuk tulisan, wedha artinya pengetahuan atau ajaran, dan tama berasal dari kata utama yang artinya baik, tinggi atau luhur. Dengan demikian, Serat Wedhatama adalah sebuah karya yang berisi pengetahuan untuk dijadikan bahan pengajaran dalam mencapai keutamaan dan keluhuran hidup dan kehidupan umat manusia. Serat Wedhatama yang memuat filsafat Jawa ini ditulis oleh Kangjeng Gusti Pangeran Arya (KGPA) Mangkunegara IV yang terlahir dengan nama Raden Mas Sudira pada hari Senin Paing, tanggal 8 Sapar, tahun Jimakir, 
Windu Sancaya, tahun Jawa 1738, atau tahun Masehi 3 Maret 1811. Sri Mangkunegara wafat pada hari Jumat tanggal 8 September 1881 pada usia 70 tahun dan telah meninggalkan warisan yang tidak ternilai harganya.

Beliau seorang raja yang terkenal adil, arif dan bijaksana yang memerintah Mangunegaran selama 25 tahun sejak 24 Maret 1853. Dalam situs http:sabdalangit.wordpress.com Serat Wedhatama dikatakan sebagai sebuah ajaran luhur untuk membangun budi pekerti dan olah spiritual bagi kalangan raja-raja Mataram, tetapi diajarkan pula bagi siapapun yang berkehendak menghayatinya. Wedhatama menjadi salah satu dasar penghayatan bagi siapa saja yang ingin "laku" spiritual dan bersifat universal lintas kepercayaan atau agama apa pun. Karena ajaran dalam Wedhatama bukanlah dogma agama yang erat dengan iming-iming surga dan ancaman neraka, melainkan suara hati nurani, yang menjadi "jalan setapak" bagi siapa pun yang ingin menggapai kehidupan dengan tingkat spiritual yang tinggi. Mudah diikuti dan dipelajari oleh siapa pun, diajarkan dan dituntun step by step secara rinci. Puncak dari "laku" spiritual yang diajarkan serat Wedhatama adalah menemukan kehidupan yang sejati, lebih memahami diri sendiri, manunggaling kawula-Gusti, dan mendapat anugerah Tuhan untuk melihat rahasia kegaiban. Serat yang berisi ajaran tentang budi pekerti atau akhlak mulia, digubah dalam bentuk tembang agar mudah diingat dan lebih "membumi". Sebab, sebaik apa pun ajaran itu tidak akan bermanfaat apa- apa, apabila hanya tersimpan di dalam "menara gadhing" yang megah.

Untuk membahas nilai moral dalam Serat Wedhatama, di bawah ini dikutip salah satu pupuh dalam Serat Wedhatama, yaitu pupuh Sinom di bawah ini. Data diambil dari buku "Menyingkaf Serat Wedhatama" (1984:34-38) oleh Anjar Any dengan penyesuaian terjemahan teks.

Nulada laku utama, tumrape wong tanah Jawi, wong agung ing Ngeksiganda, panembahan Senopati, kepati amarsudi, sudane hawa lan nepsu, pinepsu tapa brata, tanapi ing siyang ratri, amamangun karyenak tyasing sesama. (Contohlah perilaku utama, bagi kalangan orang Jawa, orang besar dari Ngeksiganda/ Mataram, Panembahan Senopati, yang tekun mengurangi hawa nafsu, dengan jalan prihatin/bertapa, serta siang malam selalu berkarya membuat hati tenteram bagi sesama).

Samangsane pasamuan, mamangun marta martani, sinambi ing saben mangsa, kala kalaning asepi, lelana teki-teki, nggayuh geyonganing kayun, kayungyun eninging tyas, sanityasa pinrihatin,puguh panggah cegah dhahar lawan nendra (Dalam setiap pertemuan/diskusi, membangun sikap tahu diri, setiap ada kesempatan, di saat waktu longgar, mengembara untuk bertapa, menggapai cita-cita hati, hanyut dalam keheningan kalbu, senantiasa menjaga hati untuk prihatin menahan hawa nafsu, dengan tekad kuat, membatasi makan dan tidur).

Saben mendra saking wisma, lelana lalading sepi, ngingsep sepuhing supana, mrih pana pranaweng kapti, tis tising tyas marsudi, mardawaning budya tulus, mesu reh kasudarman, neng tepining jalanidhi, 
sruning brata kataman wahyu dyatmika (Setiap pergi meninggalkan rumah (istana), berkelana ke tempat yang sunyi, menghirup tingginya ilmu, agar jelas apa yang menjadi tujuan hidup sejati, tekad hati selalu berusaha dengan tekun, memperdayakan akal budi, menghayati cinta kasih, ditepinya samudra, kuatnya bertapa diterimalah wahyu kebaikan).

Wikan wengkoning samodra, kederan wus den ideri, kinemat kamot hing driya, rinegan segegem dadi, dumadya angratoni, nenggih Kangjeng Ratu Kidul, ndedel nggayuh nggegana, umara marak maripih, sor prabawa lan wong agung Ngeksiganda (Memahami kekuasaan di dalam samodra seluruhnya sudah dijelajahi, dihayati dalam hati, ibarat dalam satu genggaman, berhasilah dikuasai, Kanjeng Ratu Kidul, melesat menggapai mengangkasa, datang menghadap dengan hormat, segan kepada raja Mataram).

Dahat denira aminta, sinupeket pangkat kanthi, jroning alam palimunan, ing pasaban saben sepi, sumanggem anyanggemi, ing karsa kang wus tinamtu, pamrihe mung aminta, supangate teki-teki, nora ketang teken janggut suku jaja (Memohon dengan sangat kepada beliau, agar diakui sebagai sahabat setia, di dalam alam gaib, berkelana setiap sepi, bersedialah menyanggupi, kehendak yang sudah digariskan, harapannya hanyalah meminta restu dalam bertapa, meski dengan susah payah).

Prajanjine abipraya, saturun-turuning wuri, mangkono trahing ngawirya, yen amasah mesu budi, dumadya glis dumugi, iya ing sakarsanipun, wong agung ngeksiganda, nugrahane prapteng mangkin, trah tumerah dharahe padha wibawa (Perjanjian sangat mulia, untuk seluruh keturunannya di kelak kemudian hari, begitulah seluruh keturunan orang luhur, bila mau mengasah akal budi akan cepat berhasil, apa yang diharapkan orang besar mataram, anugerahnya hingga kelak, seluruh keturunan darahnya memiliki wibawa).

Ambawani tanah jawa, kang padha jumeneng aji, satriya dibya sumbaga, tan lyan trahing senopati, pan iku pantes ugi, tinelad labetipun, ing sakuwasanira, enake lan jaman mangkin, sayektine tan bisa ngepleki kuna (Menguasai tanah Jawa, yang menjadi raja pemimpin, satria sakti termasyhur, tidak lain keturunan senopati, hal ini pantas pula sebagai tauladan budi pekertinya, sebisamu, terapkan di zaman nanti, walaupun tidak bisa persis sama seperti di masa silam).

Lowung kalamun tinimbang, ngaurip tanpa prihatin, nanging ta ing zaman mangkya, pra mudha kang den karemi, manulad nelad nabi, nayakengrat gusti rasul, anggung ginawe umbag, saben seba mampir masjid, ngajab-ajab tibaning mukjijat drajat (Sayang bila dibanding orang hidup tanpa prihatin, namun di masa yang akan datang, yang digemari anak muda, meniru-niru nabi, rasul utusan Tuhan, yang hanya dipakai untuk menyombongkan diri, setiap akan bekerja singgahdulu dimasjid,mengharap mukjizat agar mendapat derajat).

Anggung anggubel sarengat, saringane tan den wruhi, dalil dalaning ijemak, kiyase nora mikani, ketungkul mungkul sami, bengkrakan mring masjid agung, kalamun maca kutbah, lelagone dandanggendis, swara arum ngumandhang cengkok palaran 
(Hanya memahami sariat kulitnya saja, hakikatnya tidak dikuasai, pengetahuan untuk memahami makna, dan suri tauladan tidak mumpuni mereka terlena, bersikap berlebih-lebihan di masjid besar, bila membaca khotbah berirama gaya dandanggula menghanyutkan hati, suara merdu bergema gaya palaran).

Lamun sira paksa nulad, tuladhaning kangjeng nabi,o, ngger kadohan panjang$k a h$, wateke tan betah kaki, rehne ta sira Jawi, sathithik bae wus cukup, aywa guru aleman, nelad kas ngepleki pekih, lamun pangkuh pangangkah yekti karahmat (Jika kamu memaksa meniru, tingkah laku Kanjeng Nabi, oh, Nak terlalu naif, biasanya tidak akan betah Nak, karena kamu itu orang Jawa, sedikit saja sudah cukup, janganlah sekedar mencari sanjungan, mencontoh-contoh mengikuti fiqih apabila mampu, memang ada harapan mendapat rahmat).

Naging enak ngupa boga, reh ne ta tinitah langip, apata suweting nata, tani tanapi agrami, mangkono mungguh mami, padune wong dahat cubluk, durung wruh cara arab, jawaku wae tan ngenting, parandene paripaksa mulang putra (Tetapi seyogyanya mencari nafkah karena diciptakan sebagai makhluk lemah, apakah mau mengabdi kepada raja, bercocok tanam atau berdagang, begitulah menurut pemahamanku, sebagai orang yang sangat bodoh, belum paham cara Arab, tata cara Jawa saja tidak mengerti, namun memaksa diri mendidik anak).

Saking duk maksih taruna, sadhela wus anglakoni, aberag marang agama, maguru anggering kaji, sawadine tyas mami, banget wedine ing mbesuk, pranatan ngakir jaman, tan tutug kaselak ngabdi, nora kober sembahyang gya tinimbalan (Dikarenakan waktu masih muda, keburu menempuh belajar pada agama, berguru menimba ilmu pada yang haji, maka yang terpendam dalam hatiku, menjadi sangat takut akan hari kemudian, keadaan di akhir zaman, tidak tuntas keburu "mengabdi" tidak sempat sembahyang terlanjur dipanggil).

Marang ingkang asung pangan, yen kesuwen den dukani, abubrah kawur tyas ingwang, lir kiyamat saben ari, bot allah apa gusti, tambuh tambuh solahingsun, lawas lawas nggraita, rehne ta suta priyayi, yen mamriha dadi kaum temah nistha (Kepada yang memberi makan, jika kelamaandimarahi, menjadi kacau balau perasaanku,sepertikiyamat saban hari, berat "Allah" atau "Gusti", bimbanglah sikapku, lama-lama berfikir karena anak turun priyayi, bila ingin jadi juru doa dapatlah nista)

Tuwin ketip suragama, pan ingsun nora winaris, angur baya ngantepana, pranatan wajibing urip, lampahan angluluri, $\mathrm{ku}$ na kumunanira, kongsi tumekeng samangkin, kikisane tan lyan amung ngupa boga (Begitu pula jika aku menjadi pengurus dan juru dakwah agama karena aku bukanlah keturunannya, lebih baik memegang teguh aturan dan kewajiban hidup, menjalankan pedoman hidup warisan leluhur dari zaman dahulu kala hingga kelak kemudian hari, ujungnya tidak lain hanyalah mencari nafkah)

Bonggan kan tan merlok-na, mungguh ugering ngaurip, uripe lan tri prakara, wirya arta tri winasis, kalamun kongsi sepi, saka wilangan tetelu, telas tilasing janma, aji godhong jati aking, temah papa papariman ngulandara (Salahnya sendiri yang 
tidak mengerti, pedoman orang hidup itu demikian seyogyanya, hidup dengan tiga perkara, keluhuran harta, tiga ilmu pengetahuan, bila tak satu pun dapat diraih dari ketiga perkara itu, habis lah harga diri manusia, lebih berharga daun jati kering, akhirnya mendapatlah derita, jadi pengemis yang terlunta).

Kang wus waspada ing patrap, manganyut ayat winasis, wasana wosing jiwangga, melok tanpa aling-aling, kang ngalingi kalingling, wenganing rasa tumlawung, keksi saliring jaman, angelangut tanpa tepi, yeku ingaran tapa tapaking Hyang Suksma (Yang sudah paham tata caranya, mengikuti ajaran utama, jika berhasil merasuk ke dalam jiwa, akan melihat tanpa penghalang, yang menghalangi tersingkir, terbukalah rasa sayup menggema, tampaklah seluruh cakrawala, sepi tiada bertepi, yaitu bertapa mengikuti Hyang Sukma).

Mangkono janma utama, tuman tumanem ing sepi, ing saben rikala mangsa, masah amemasuh budi, laire anetepi, ing reh kasatriyanipun, susilo anor raga, wignya met tyasing sesami, yeku aran wong barek berag agama (Demikianlah manusia utama, gemar di dalam ketenangan, di saat-saattertentu, mempertajam dan membersihkan budi, bermaksud memenuhi tugasnya sebagai satria, berbuat susila rendah hati, pandai menyejukkan hati pada sesama, itulah sebenarnya yang disebut menghayati agama).

Ing jaman mengko pan ora, arahe para taruni, yen antuk tuduh kang nyata, nora pisan den lakoni, banjur njujurken kapti, kakekne arsa winuruk, ngandelken gurunira, pandhitane praja sidik, tur wus manggon pamucunge mring makripat (Di zaman kelak tidak demikian, sikap anak muda bila mendapat petunjuk nyata, tidak pernah dijalani, lalu hanya menuruti kehendaknya, kakeknya akan diajari, mengandalkan gurunya, yang dianggap sebagai pendeta, serta sudah menguasai makrifat).

Dari pupuh tembang Sinom tersebut bait yang mengandung ajaran moral adalah bait satu sampai bait tiga, yang isinya menyarankan agar orang Jawa mencontoh perilaku utama Raja Mataram Panembahan Senapati, yaitu mengurangi hawa nafsu, dengan jalan prihatin (bertapa), siang malam selalu berkarya membuat hati tenteram memberi kasih sayang bagi sesama. Setiap ada kesempatan mengembara untuk bertapa, menggapai cita-cita hati, hanyut dalam keheningan kalbu. Senantiasa menjaga hati untuk prihatin (menahan hawa nafsu), dengan tekad kuat, membatasi makan dan tidur. Setiap pergi meninggalkan rumah, berkelana ke tempat yang sunyi, menghirup tingginya ilmu, agar jelas yang menjadi tujuan hidup sejati. Tekad hati selalu berusaha dengan tekun, memperdayakan akal budi, menghayati cinta kasih, bertapa untuk menerima wahyu kebaikan.

Bait keempat sampai keenam memberi contoh kepada kita agar suka menjelajah mencari ilmu memohon Tuhan agar seluruh keturunannya di kelak kemudian hari menjadi keturunan orang luhur. Diingatkan juga bila mau mengasah akal budi maka akan cepat berhasil sehingga apa yang diharapkan akan berhasil hingga kelak dan seluruh keturunan darahnya memiliki wibawa.

Bait ketujuh sampai sepuluh mengingatkan kepada anak-anak muda yang hanya mencontoh sebagian yang dila- 
kukan nabi dengan tujuan untuk menyombongkan diri, pergi ke masjid hanya ikut-ikutan agar terlihat orang yang taat beribadah dan semata-mata hanya mengharap keperluan duniawi. Pada bait ke sembilan diingatkan agar jangan terlena belajar agama tetapi tidak mengamalkannya, akhirnya belum sempat mengamalkan agama keburu dipanggil yang Maha Kuasa.

Bait dua belas sampai empat belas mengingatkan generasi muda agar semampang masih muda untuk belajar budaya Jawa (padune wong cubluk, $d u$ rung weruh cara arab, jawaku wae tan ngenting, parandene paripaksa mulang putra). Pada bait empat belas dijelaskan agar generasi muda lebih baik memegang teguh aturan dan kewajiban hidup, menjalankan hidup warisan leluhur dari zaman dahulu hingga kelak kemudian hari (pranatan wajibing urip, lampahan angluluri, kuna kumunanira, kongsi tumekeng samangkin).

Bait lima belas sampai delapan belas mengandung ajaran moral pedoman hidup yang terdiri dari tiga hal, yaitu keluhuran (kekuasaan), harta (kesejahteraan), dan ilmu pengetahuan. Apabila satu hal dari tiga perkara itu tidak dapat diraih, maka habislah harga diri manusia, lebih berharga dari daun jati kering, akhirnya mendapatlah derita, jadi pengemis dan terlunta. Perkara pertama, untuk meraih kedudukan yang baik, seseorang harus bekerja tanpa mengenal pamrih di mana pun ia berada. Perkara kedua, bagaimana orang harus meraih kekayaan. Mangkunegara IV menganjurkan agar orang harus bekerja giat untuk memperoleh kekayaan. Perkara ketiga yang harus dicapai adalah kepandaian, atau menuntut ilmu yang akan bermanfaat bagi kehidupan.

Dengan melihat fakta-fakta ajaran moral yang ada, ajaran moral yang terkandung dalam Serat Wedhatama ini senafas dengan makna "baik" menurut aliran cultural relativism yang diuraikan oleh Harry J. Gensler dalam buku "Ethics" yang telah dikutib di atas. Di sini, ajaran yang disampaikan sudah turun-menurun sejak jaman kerajaan Mataram dan hanya berlaku dalam kalangan Jawa, meskipun kalau dilihat dari sisi substansi ada yang bersifat universal. Tampaknya, ke depan seperti yangdiungkapkan oleh Sudiardja (2009: 2) masyarakat pada umumnya akan menerima ajaran relativisme, yang kemudian berkembang dalam faham Relativisme Kultural, yang mengartikan moral sebagai konvensi budaya yang tidak saja berubah-ubah, melainkan juga berbeda-beda dari satu daerah ke daerah lain. Suseno (1993:223-225) dalam buku "Etika Jawa" menengerai bahwa etika Jawa termasuk relativisme etis, tepatnya relativisme deskriptif kultural, di mana prinsip-prinsip moral dari individu-individu atau kelompok-kelompok yang berbeda sering berbeda dan bertentangan secara fundamental. Masalah relativismne muncul karena "etika Jawa" berbeda dari "etika barat". Relativisme etis pada umumnya bertolak dari penilaian-penilaian dan norma-norma moral yang jelas bertentangan satu sama laindalam masyarakat-masyarakat yang berbeda. Konsep mencontoh perilaku utama Panembahan Senapati, dengan tekun, mengurangi hawa nafsu, dengan jalan prihatin (bertapa), serta siang malam selalu berkarya membuat hati ten- 
teram memberi kasing sayang bagi sesama adalah khas ajaran moral Jawa dan tidak ada di tempat lain; yang ada di tempat lain adalah ajaran kasih sayang pada sesama (amamangun karyenak tyasing sesama) sebagaimana dikatakan oleh Suseno, memang terdapat ajaran moral yang universal, yaitu pada norma-norma dasar, perbedaannya hanya pada pembobotan.

Selanjutnya, ajaran bertapa untuk menerima wahyu kebaikan sebagaimana dinyatakan pada bait ketiga, yaitu "saben mendra saking wisma, lelana lalading sepi, ngingsep sepuhing supana, mrih pana pranaweng kapti, titising tyas marsudi, mardawaning budya tulus, mesu reh kasudarman, neng tepining jalanidhi, sruning brata kataman wahyu dyatmika terkandung ajaran berbuat sesuatu agar kelak mendapatkan imbalan. Hal itu senafas dengan aliran consequentialism (Gensler, 1998:138;156) yang mengajarkan kepada kita untuk melakukan tindakan apa pun yang mempunyai konsekuensi atau dampak terbaik. Menurut consequentialism, kita harus melakukan sesuatu yang bisa memberikan dampak lebih baik dan menyingkirkan dampak yang tidak baik bagi tindakan kita.

Ajaran lain yang senafas adalah supernaturalism, yang mengatakan bahwa moral hukum menjelaskan kehendak Tuhan. Supernaturalism berpendapat bahwa hukum moral Tuhan akan menjelaskan: "X adalah baik" berarti "Allah menghendaki X." Ajaran moral pada bait dua belas sampai empat belas senafas dengan aliran supernaturalism, di mana generasi muda agar memegang teguh aturan dan kewajiban hidup, menjalankan hidup warisan leluhur da- rizaman dahulu hingga kelak kemudian hari (pranatan wajibing urip, lampahan angluluri, kuna kumunanira, kongsi tumekeng samangkin).

\section{PENDIDIKAN BUDI PEKERTI}

Pendidikan budi pekerti yang pernah menjadi isu nasional tatkala pengembangan kurikulum 1994, kini mencuat kembali seiring dengan dirasakannya menurunnya nilai-nilai moral, terutama di kalangan generasi muda. Sampai sekarang masih sering disuarakan oleh sebagian masyarakat agar pendidikan budi pekerti menjadi mata pelajaran wajib di semua jenjang pendidikan. Sementara kelompok masyarakat lainnya menyuarakan agar pendidikan budi pekerti tidak perlu masuk secara khusus sebagai mata pelajaran tersendiri karena sudah tercakup dalam beberapa mata pelajaran yang terkait, seperti Pendidikan Pancasila, Pendidikan Agama, Bahasa Indonesia, Ilmu Pengetahuan Sosial, Mata Pelajaran Muatan Lokal, dan lainnya. Terlepas dari dua pendapat tersebut, pada mata pelajaran muatan lokal syarat akan nilainilai lokal yang dapat dijadikan bahan pendidikan budi pekerti.

Muatan lokal wajib pada sekolah mulai dari SD sampai SMA di Provinsi Daerah Istimewa Yogyakarta, Jawa Tengah, dan Jawa Timur adalah Mata Pelajaran Bahasa, Sastra, dan Budaya Jawa. Serat Wedhatama, yang merupakan karya besar Sri Mangkunegara IV dapat dijadikan rujukan utama dalam pembelajaran muatan lokal Bahasa, Sastra, dan Budaya Jawa karena di dalamnya berisi ajaran moral tentang kebijakan hidup yang berisi ajaran moral 
hidup sederhana, kasih sayang, tanggung jawab, mengembangkan akal budi, menghayati cinta kasih kepada sesama, rendah hati, tidak sombong, taat beribadah dengan menjalankan syariat agama dan meninggalkan laranganNya, meraih kedudukan yang baik dengan bekerja tanpa mengenal pamrih di mana pun ia berada, meraih kekayaan dengan bekerja keras, dan menuntut ilmu yang bermanfaat bagi peradaban dunia. Hal itu, seiring dengan pelaksanaan pendidikan karakter yang telah dicanangkan oleh Menteri Pendidikan Nasional Republik Indonesia bertepatan dengan hari Pendidikan Nasional tahun 2010 yang jatuh pada tanggal 2 Mei 2010.

\section{PENUTUP}

Berdasarkan pembahasan di atas dapat disimpulkan bahwa nilai moral merupakan nilai tertinggi. Nilai moral memilik ciri-ciri berkaitan dengan pribadi manusia yang bertanggung jawab, berkaitan dengan hati nurani, mewajibkan manusia secara absolut dan tidak bisa ditawar-tawar, dan bersifat formal. Nilai moral berkaitan juga dengan apa yang seyogianya tidak dilakukan karena berkaitan dengan prinsip moralitas yang ditegakkan. Nilai moral berarti tata nilai dalam arti "baik".

Nilai moral dalam Serat Wedhatama adalah hidup sederhana, kasih sayang, tanggung jawab, mengembangkan akal budi, menghayati cinta kasih kepada sesama, rendah hati, tidak sombong, taat beribadah dengan menjalankan syariat agama dan meninggalkan larangan, meraih kedudukan yang baik dengan bekerja tanpa mengenal pamrih di mana pun ia berada, meraih kekayaan dengan bekerja keras, dan menuntut ilmu yang bermanfaat bagi kehidupan dunia. Nilai-nilai yang demikian merupakan nilai moral yang memiliki empat ciri, yaitu berkaitan dengan pribadi manusia yang bertanggung jawab, berkaitan dengan hati nurani, berkaitan dengan kewajibkan manusia secara absolut dan tidak bisa ditawar-tawar, dan bersifat formal.

Serat Wedhatama dapat dijadikan rujukan utama dalam pembelajaran muatan lokal Bahasa, Sastra, dan Budaya Jawa karena di dalamnya berisi nilainilai moral yang dapat dijadikan bahan pendidikan budi pekerti yang merupakan salah wujud pelaksanaan pendidikan karakter.

\section{UCAPAN TERIMA KASIH}

Akhirnya perlu disampaikan di sini, penulis mengucapkan terima kasih kepada semua pihak yang telah membantu terwujudnya tulisan ini. Terima kasih juga, penulis ucapkan kepada Redaksi Jurnal Cakrawala Pendidikan yang telah membantu mengedit dan mewujudkan tulisan ini dimuat dalam Jurnal Ilmiah Cakrawala Pendidikan.

\section{DAFTAR PUSTAKA}

Anjar, Any. 1984. Menyingkap Serat Wedhatama. Semarang: CV Aneka Ilmu.

Gensler, Harry J. 1998. Ethics. London and New York. Routledge.

Jatmiko, Adityo. 2005. Tafsir Ajaran Serat Wedhatama. Yogyakarta: Pura Pustidaka. 
Suseno, Frans Magnis. 2008. Etika Abad Kedua Puluh. Yogyakarta: Kanisius. 2005. Pijar-pijar Filsafat. Yogyakarta: Kanisius . 1993. Etika Jawa. Jakarta: Gramedia Pustidaka Utama.

Bertens, K. 1993. Etika. Jakarta: Gramedia Pustidaka Utama.

Frondizi, Risieri. 2007. Pengantar Filsafat Nilai (terjemahan dari buku What is Value? Oleh Cuk Ananta Wijaya). Yogyakarta: Pustidaka Pelajar.
Rachels, James. 2004. Filsafat Moral (terjemahan dari buku The Element of Moral Philosophy oleh A. Sudiarja). Yogyakarta: Kanisius.

Soejadi. 1999. Pancasila sebagai Sumber Tertib Hukum Indonesia. Yogyakarta: Lukman Offset.

Sudijardja SJ, A. 2009. "Kompleksitas Persoalan Moral". Yogyakarta: Bahan Kuliah Etika.

Wiramihardja, A. Sutarjo. 2007. Pengantar Filsafat (Sistematika Filsafat, Sejarah Filsafat, Lodika dan Filsafat Ilmu 'Epistemologi', Metafisika dan Filsafat Manusia, dan Aksiologi). Bandung Aditama. 